\title{
DETERMINATION OF NUMBER AND CONFIGURATION OF CANALS IN PERMANENT LOWER FIRST MOLAR BY CONE BEAM COMPUTED TOMOGRAPHY
}

\section{Tehmina Marwat ${ }^{\natural}$, Neelofar Nausheen ${ }^{2}$, Umar Nasir $^{3}$}

\section{ABSTRACT}

OBJECTIVE: To determine the number and configuration of canals in permanent lower first molar by cone beam computed tomography (CBCT).

METHODS: This cross-sectional study was conducted at Sardar Begum Dental College, Peshawar, using 334 good quality CBCT images of mandibular first molar with intact pulp, closed apices from both genders using previous records. $\mathrm{CBCT}$ images were analyzed using Scanora software version $3 \mathrm{D}$. All the images were studied at axial and coronal planes by continuously moving the tool bar from the floor of pulp chamber to root apices.

RESULTS: Out of 334 patients, 210 (62.9\%) were males and 124 (37.1\%) were females. Three-canals were the most frequent $(n=167 ; 50 \%)$ canals in permanent lower first molar followed by four-canals $(n=|4| ; 42.2 \%)$ and twocanals $(n=26 ; 7.8 \%)$. In males, four-canals pattern was most common $(51.4 \%)$ while in females three-canals pattern was most frequent $(57.3 \%)[P=0.000]$. Type II was the common $(n=203 ; 60.78 \%)$ configuration in mesial root of mandibular first permanent molar followed by type IV $(n=116 ; 34.7 \%)$ and type I $(n=15 ; 4.5 \%)$. In distal root of mandibular first permanent molar, 180 $(53.9 \%)$ cases had type I canal configuration followed by type IV $(n=92 ; 27.5 \%)$ and type II $(n=62 ; 18.6 \%)$. Gender stratified data was significant for distal root while insignificant for mesial root.

CONCLUSION: Males had common patterns of four-canals while females had three-canals. Canal configuration in mesial root was type II followed by type IV and distal root was type I followed by type IV and II.

KEY WORDS: Molar (MeSH); Cone Beam Computed Tomography (MeSH); Canal Configuration (MeSH).

THIS ARTICLE MAY BE CITED AS: Marwat T, Nausheen N, Nasir U. Determination of number and configuration of canals in permanent lower first molar by cone beam computed tomography. Khyber Med Univ J 20I9; I I(I):32-6. DOI: I0.35845/kmuj.20I9.18757.

\section{INTRODUCTION}

P ermanent mandibular first molar erupt at the age of six to seven years and its root completion occurs after two to three years. Lower first molar has five cusps and has a root trunk which divides into mesial and distal roots. Rarely, it exhibits three roots where the mesial root has buccal and lingual branches.' Among all human teeth, the lower first permanent molar is commonly affected by caries and usually needs restoration and root canal treatment at early age. ${ }^{2}$ The incidence of caries in first molar is $55.6 \%{ }^{3}$ This is due to the early eruption of mandibular first permanent molar. This is first one in permanent dentition to erupt and that's why more prone to cariogenic insults. ${ }^{2}$ There are different causes of root canal treatment failure which include deficient cleaning and sealing of canals, inadequate coronal restoration and missing of canal due to
I Demonstrator, Department of Oral Biology, Khyber Medical University Institute of Dental Sciences (KMU-IDS), Kohat, Pakistan \& M. Phil Scholar, Sardar Begum Dental College (SBDC), Gandhara University (GU), Peshawar, Pakistan. Email『: dr.tehmaj@gmail.com

2 Assistant Professor, Department of Oral Biology, SBDC, GU, Peshawar, Pakistan

3 Assistant Professor, Department of Oral Biology, KMU-IDS, Kohat, Pakistan

Date Submitted:

Date Revised:

October 30, 2018

Date Accepted:

March 20, 2019

March 22, 2019

two dimensional images. Various procedures were undertaken to find out the number of root canals e.g. decalcification method, periapical radiograph, spiral computed tomography, scanning electron microscopy, cone beam computed tomography (CBCT). The disadvantage of decalcification method is formation of opaque area owing to incomplete dehydration and air drying. Periapical radiographs are two dimensional images. ${ }^{4}$ The spiral computed tomography method provides three dimensional image but the major limitation of this method is high radiation dose $(1.34 \mathrm{mSv}) .^{5}$ The limitation of scanning electron microscopy is the potential for artifact production during specimen's preparation. ${ }^{6} \mathrm{CBCT}$ images are three dimensional and provide more image accuracy. It has rapid scanning time (10$70 \mathrm{sec})$ and radiation dose is low $(0.034-$ $0.102 \mathrm{mSv})^{7}$

Different previous investigations have documented variations in root canal systems in different races. ${ }^{8}$ The lower molars with two roots usually have three canals but the incidence of fourth canal is also high. ${ }^{2,8-10}$ Mesial root has two canals and the distal root has one or two canals. ${ }^{4}$ A study in Iran declared that $6 \%$ of teeth had three roots, $50 \%$ had four canals and $42 \%$ had three canals. 8 In a study in Turkey evaluated configuration of root canal in lower first permanent molar with the help of CBCT, they reported that type IV configuration was the most numerous $59.8 \%$, type II was the second most common $32.5 \%$ in mesial root while type I was found in $73.5 \%$ cases and in $12.9 \%$ cases was type II in distal root for which Vertucci's classification was used. ${ }^{7}$ Zhang R, et al. ${ }^{4}$ 
TABLE I: STRATIFICATION OF CANAL NUMBERS WITH GENDER

\begin{tabular}{|c|c|c|c|c|c|c|}
\hline \multirow{3}{*}{$\begin{array}{l}\text { Number } \\
\text { of Canals }\end{array}$} & \multicolumn{3}{|c|}{ Gender of Patients } & \multirow{3}{*}{$x^{2}$} & \multirow{3}{*}{ df } & \multirow{3}{*}{${ }^{*}$ p-value } \\
\hline & Male & Female & Total & & & \\
\hline & n (\%) & n (\%) & n (\%) & & & \\
\hline 2 & $6(2.9)$ & $20(16.1)$ & $26(7.8)$ & \multirow{4}{*}{31.092} & \multirow{4}{*}{2} & \multirow{4}{*}{.000} \\
\hline 3 & $96(45.7)$ & $71(57.3)$ & $167(50)$ & & & \\
\hline 4 & $108(5 \mid .4)$ & $33(26.6)$ & $|4|(42.2)$ & & & \\
\hline Total & $210(100)$ & $124(100)$ & $334(100)$ & & & \\
\hline
\end{tabular}

*Chi-Square applied.

TABLE II: STRATIFICATION OF CANAL CONFIGURATION (MESIAL ROOT) WITH GENDER

\begin{tabular}{|c|c|c|c|c|c|c|}
\hline \multirow{3}{*}{$\begin{array}{l}\text { Number } \\
\text { of Canals } \\
\text { (Mesial } \\
\text { Root) }\end{array}$} & \multicolumn{3}{|c|}{ Gender of Patients } & \multirow{3}{*}{$x^{2}$} & \multirow{3}{*}{ df } & \multirow{3}{*}{ *p-value } \\
\hline & Male & Female & Total & & & \\
\hline & $n(\%)$ & n (\%) & $n(\%)$ & & & \\
\hline 1 & $6(2.9)$ & $9(7.3)$ & $15(4.5)$ & \multirow{9}{*}{4.535} & \multirow{9}{*}{7} & \multirow{9}{*}{.104} \\
\hline II & $134(63.8)$ & $69(55.6)$ & $203(60.8)$ & & & \\
\hline III & 0 & 0 & 0 & & & \\
\hline IV & $70(33)$ & $46(37.1)$ & $116(34.7)$ & & & \\
\hline $\mathrm{V}$ & 0 & 0 & 0 & & & \\
\hline $\mathrm{VI}$ & 0 & 0 & 0 & & & \\
\hline VII & 0 & 0 & 0 & & & \\
\hline VIII & 0 & 0 & 0 & & & \\
\hline Total & $210(100)$ & $124(100)$ & $334(100)$ & & & \\
\hline
\end{tabular}

*Chi-Square applied.

TABLE III: STRATIFICATION OF CANAL CONFIGURATION (DISTAL ROOT) WITH GENDER

\begin{tabular}{|c|c|c|c|c|c|c|}
\hline \multirow{3}{*}{$\begin{array}{l}\text { Number } \\
\text { of Canals } \\
\text { (Distal } \\
\text { Roots) }\end{array}$} & \multicolumn{3}{|c|}{ Gender of Patients } & \multirow{3}{*}{$x^{2}$} & \multirow{3}{*}{ df } & \multirow{3}{*}{ *p-value } \\
\hline & Male & Female & Total & & & \\
\hline & $n(\%)$ & n (\%) & n (\%) & & & \\
\hline 1 & $102(48.6)$ & $78(62.9)$ & $180(53.9 \%)$ & \multirow{9}{*}{7.846} & \multirow{9}{*}{7} & \multirow{9}{*}{.020} \\
\hline II & $40(19)$ & $22(17.7)$ & $62(18.6 \%)$ & & & \\
\hline III & 0 & 0 & 0 & & & \\
\hline IV & $68(32.4)$ & $24(19.4)$ & $92(27.5 \%)$ & & & \\
\hline $\mathrm{V}$ & 0 & 0 & 0 & & & \\
\hline $\mathrm{VI}$ & 0 & 0 & 0 & & & \\
\hline VII & 0 & 0 & 0 & & & \\
\hline VIII & 0 & 0 & 0 & & & \\
\hline Total & $210(100)$ & $124(100)$ & 334 & & & \\
\hline
\end{tabular}

*Chi-Square applied.

evaluated lower permanent $1^{\text {st }}$ and $2^{\text {nd }}$ molar's root canal configuration in subpopulation of China using CBCT on 389 Chinese individuals. Their results showed that in $70 \%$ of lower first molars and $76 \%$ of lower $2^{\text {nd }}$ molars cases had two isolated roots. In $29 \%$, first molars were tri-rooted. In $29 \%$ of second molars, roots canal were Cshaped. Three canals frequency was $56 \%$ and four canal frequencies was $43 \%$ in lower $1^{\text {st }}$ molar while in $2^{\text {nd }}$ molar and was $46 \%$ and $38 \%$ respectively. Vertucci type I configuration was most common in distal root. The root canal systems were more intricate in mesial root. Seven variants of morphology of root canal were found in lower $\mathrm{I}^{\text {st }}$ molar and eight in lower $2^{\text {nd }}$ molars.

A local study was done in 2015 by decalcification method. They have shown that $100 \%$ of permanent lower first molar are two rooted. They also revealed that prevalence of three canals was $65.8 \%$ and four canals were $34.2 \%$ (two in each root). They also concluded that mesial root was dominated by type
IV configuration $(70.7 \%)$ followed by type II $(26.8 \%)^{5}$

For successful root canal treatment, dentists must know the number of root canals, cleaned and irrigated them properly, and after that, fill the root canals with non reactive obturating material. If canal is missed during root canal treatment it will lead to failure of root canal treatment because it will be a source of infection. ${ }^{5,6}$ Furthermore, there is also variation in root anatomy of permanent lower first molar in different races. So this current study aims to evaluate canal numbers and configuration of lower first molar by CBCT method.

\section{METHODS}

This retrospective study was conducted at Department of Oral Diagnosis and Department of Radiology, Sardar Begum Dental College, Peshawar, Pakistan after taking prior permission from Ethical Review Committee of Gandhara University, Peshawar, Pakistan. CBCT images, scanned from March 2015 to April 2016, were collected from the said departments and analyzed during the study duration.

CBCT images were analyzed using Scanora software version 3D. The contrast and brightness of the images were adjusted using the imaging process tool in the software to ensure optimal visualization. All the images were studied at axial and coronal planes by continuously moving the tool bar from the floor of pulp chamber to root apexes. The data collected were strictly used for research purpose and will be kept confidential. The canal numbers and configuration were assessed and charted down in a predesigned check list according to the classification by Vertucci. ${ }^{8}$ Sample size of 334 was taken for the study. All good quality $\mathrm{CBCT}$ images of permanent mandibular first molar with intact pulp chamber, having close root apices in both genders were included in the study, while all with any treatment history, artificial crown, fractured, sclerosed roots and three rooted permanent mandibular first molars were excluded. Data was collected and analyzed using SPSS version 20. Means and standard 
deviations were calculated for number of canals. Percentage was calculated for canal configuration. Post stratification for genders were carried out for number of canals and configuration of canals using Chi-square test. $\mathrm{P}<0.05$ was considered significant.

\section{RESULTS}

Of total 334 patients, $210(62.9 \%)$ were males and 124 (37.1\%) were females. The male to female ratio was 1.6:I. Frequencies and percentages of canals' number in mandibular first permanent molar shows that three-canals were the most frequent $(50 \%)$ canals in permanent lower first molar followed by four-canals $(42.2 \%)$ and two-canals (7.8\%). Stratified gender distribution in comparison with number of root canals is shown in Table l.

Type II was the common $(n=203$; $60.78 \%$ ) configuration in mesial root of mandibular first permanent molar followed by type IV $(n=116 ; 34.7 \%)$ and type I $(n=I 5 ; 4.5 \%)$. The stratified data for configuration of canal (mesial root) in comparison with gender is as per Table Il.

In distal root of mandibular first permanent molar, 180 (53.9\%) cases had type I canal configuration followed by type IV $(n=92 ; 27.5 \%)$ and type II $(n=62 ; 18.6 \%)$. The stratified data for configuration of canal (distal root) in comparison with gender is as per Table III.

\section{DISCUSSION}

The most common cause of root canal failure is to explore and debride the whole canal." Undetected extra canal is also major cause for endodontic treatment failure. ${ }^{12}$ A precise and accurate radiography is essential for diagnosis. Radiograph taken at different angles are required for evaluation of root canal morphology and anatomy. ${ }^{13}$

In the current study males were outnumbered than females. In our country, males are dominant, more outgoing and more visitors for endodontic treatment. The second reason that the female are more cautious about their oral hygiene and hence less prone to carious lesion.
Hussain $U$, et al. ${ }^{9}$ carried out a study on incidence of fourth canal in mandibular first molars in Khyber College of Dentistry, Peshawar, their study shows similar to current study being males were more than females.

In current study $\mathrm{CBCT}$ was used to determine number and configuration of canals in permanent mandibular first molar at Peshawar. Mokhtari $\mathrm{H}$, et al. ${ }^{14}$ in vitro study compared the accuracy of $\mathrm{CBCT}$ and with staining and clearing technique in determining root canal morphology of lower first molars. They reported that clearing technique had more accuracy than cone beam CT because more accurate anatomy of the root canal system of lower first molars can be obtained. But this study has limitation because it was in vitro. In vitro study, the clearing technique can be performed more easily as compared to in vivo. $C B C T$ can reconstruct the 3-D structure of the entire root canal system to offer the dental specialist with a precise image of root canal. ${ }^{15} \mathrm{CBCT}$ is simple and non-invasive technique and can be done in any sort of clinical settings. The plus points of Cone Beam $\mathrm{CT}$ is; it is non-invasive, providing three-dimensional reconstruction for the whole canal system, radiation dose is much less, limiting imaging field is feasible, an increase in image precision and resolution and a reduction in artifacts. $^{16}$

Most of studies carried out in Pakistan only determined number of canals in first permanent molars and based on conventional X-ray (SLOB rule) and decalcification method. ${ }^{5,9,17}$ The current study addressed the number of canal as well as configuration based on CBCT method. In the present study three canals were the most numerous (50\%) followed by four canals (42.2\%). Two canals were found in $(7.8 \%)$ cases only. Shahi $S$, et al. ${ }^{8}$ conducted a study on Iranian population using extracted first permanent molars and they reported that out of 209 teeth studied, 137 teeth $(65.56 \%)$ had three canals, 66 teeth ( $31.57 \%)$ had four and 6 teeth $(2.87 \%)$ had two canals.

Hussain $U$, et al. ${ }^{9}$ reported in a study on a sample of Peshawar population based on conventional X-ray (SLOB rule) that mandibular first molar have three canals in $60 \%$ and four canals $40 \%$. The small difference in frequencies of canal patterns is due to the fact in Hussain $U$, et al. ${ }^{9}$ study, canal's frequencies were determined by house surgeons which have less experience. The second reason may be the lack of accurate diagnostic tool (e.g. CBCT). Another study conducted in Hyderabad, Pakistan, using SLOB rule showed that $36 \%$ of the mandibular first molars have four canals. ${ }^{17}$

Huang CC, et al. ${ }^{18}$ used CBCT to determine the number of roots and canals in lower first molars in 151 patients of Taiwan population. They reported that $56.1 \%$ had three canals, $40.5 \%$ had four, and $3.4 \%$ had two canals. These results are in consistence to the current study with same methodology used.

Nur BG, et al. ${ }^{19}$ determined the number of root canals and configuration of canals in lower first permanent molar in Turkish population of south-eastern area with help of CBCT of 966 samples. They reported that $49.8 \%$ had four canals, $49.8 \%$ had three canals and $0.4 \%$ had five canals. In contrast to this study, Nur BG, et al. ${ }^{19}$ found fifth canal in Turkish population as well. This may be due to genetic, environmental and ethnic variation. Accordingly in the current study about $7 \%$ patients had two canals while the Nur BG, et al. ${ }^{19}$ reported none for two canals.

In the current study gender wise distribution for number of canals shows that in males, four canals patterns were the most common (5I.4\%) followed by three canals $(45.7 \%)$ while in females three canals was most numerous (57.3\%) followed by four canals $(26.6 \%)$. This difference in frequencies of canals in both genders were statistically significant $(P=0.000)$. This unique difference may shows that number of canals is influenced by $X$ linked genetics. ${ }^{20}$ Miloglu $\mathrm{O}$, et al. ${ }^{7}$ while evaluating root and canal configuration of mandibular first molars with cone beam computed tomography in a Turkish population reported a nonsignificant difference for number of roots among males and females but not provided any data regarding canal variation stratified by gender. No study has been traced in which comparison 
among genders for number of canals in mandibular first molar was done.

In the present study Vertucci classification was used for studying root canal morphology. The distribution of canals in mesial roots mandibular first molar shows that type II was the common configuration (60.78\%). Fifteen cases $(4.49 \%)$ had type I canal configuration, 203 cases had type II canal configuration and II 13 (34.74\%) cases had type IV canal configuration. Shahi S, et al. ${ }^{8}$ reported that type IV type was the most common in Iranian population. They reported that out of 206 two-rooted mandibular first molars, mesial roots with two canals were of type II (4I.87\%), type III $(0.49 \%)$, type IV $(53.69 \%)$ or type V (3.94\%) canal configuration. It looks that race and ethnicity are imperative factors in differences perceived in root canal configuration between others in present study.

In current study, both males and females, type II canal configuration was most common in mesial root. In male $63.8 \%$ and in females $55.6 \%$ have type II configuration. In both genders, type II was most numerous followed by type IV and then type I. This difference was not statistically significant $(P=0.104)$ The research of Wasti, et al. ${ }^{2 .}$ and Gulabivala, et al. ${ }^{22}$ Sertet, et al. ${ }^{23}$ also concluded that both gender and ethnic origin should be given due consideration during preoperative evaluation of endodontic therapy. Therefore, further studies are needed in different regions of the world to prove that there is a relationship between the racial and ethnic differences and the anatomic differences in the lower first permanent molars.

Torres A, et al. $^{24}$ studied root canal configuration in mandibular first molar in sample of Belgium and Chilean population using CBCT images of 515 mandibular molars. They determined the root canal configuration on basis of Vertucci classification. They reported that the most common configurations in the mesial root of both molars were type V (42\%) and type III (33\%). These results are different from the current study. The difference may due to genetic and ethnic variation. In contrast to our study, Nur BG, et al. ${ }^{19}$ CBCT based study found type IV followed by type I canal to be the most numerous in mesial root of mandibular first molars in Iran population.

In present study the distal root of mandibular first permanent molar, 180 cases $(53.89 \%)$ had type I canal configuration, 62(18.56\%) had type II and $92(27.54 \%)$ had type IV canal configuration. Similar to the current study, Torres A, et al. ${ }^{24}$ in a study on sample of Belgium and Chilean population reported type I canal configuration to be most numerous in distal root of mandibular first molar. However, simultaneously, in contrast to the present results, in their study the second most common configuration in distal root was type III. This shows that how much variability exist in different population for canal configuration.

Nur BG, et al..$^{19}$ in a study on southeastern Turkish population reported that the most common configuration in distal root of mandibular first molar was type I followed by type II. These results are consistence with the current study. In current study no statistical difference was found for distal root canal configuration between males and females. Similar results has been reported by others. ${ }^{21,24}$

\section{CONCLUSION}

Half of mandibular first molar had threecanals. More males have common patterns of four canals while in female three canal was the commonest pattern. More males have common patterns of four-canals while in female three-canal was the commonest pattern. Mesial and distal roots have different patterns of canal configuration. Mesial root has type II most common canal configuration and distal root has type I most common canal configuration.

\section{REFERENCES}

I. Fuller JL, Denehy GE, Hall SA. Concise dental anatomy and morphology: $2^{\text {nd }}$ ed. lowa. University of lowa College of Dentistry 1999. 164-83.

2. Mãrgãrit R, Andrei OC. Anatomical variations of mandibular first molar and their implications in endodontic treatment. Rom J Morphol Embryol 201 I; 52(4): I389-92.

3. Demirci M, Tuncer S, Yuceokur AA. Prevalence of caries on individual tooth surfaces and its distribution by age and gender in university clinic patients. Eur J Dent 20 I0; 4(3):270 9.

4. Zhang R, Wang H, Tian Y, YuX, Hu T, Dummer PMH. Use of cone-beam computed tomography to evaluate root and canal morphology of mandibular molars in Chinese individuals. Int Endod J 201 I;44(II):990-9. DOI:10.1III/ j.I365-259l.201 I.01904.x.

5. Faraz SA, Tariq A, Jameel A. Root canal morphology of mandibular first permanent molar-Karachi sample. Pak Oral Dent J 20I5; 35(2):294-8.

6. Woelfel JB, Scheid RC. Dental anatomy: its relevance to dentistry: $6^{\text {th }}$ ed. Columbus, Williams \& Wilkins 1997; I 78-9.

7. Miloglu $\mathrm{O}$, Arslan $\mathrm{H}$, Barutcigil $\mathrm{C}$, Cantekin K. Evaluating root and canal configuration of mandibular first molars with cone beam computed tomography in a Turkish population. J Dent Sci 2013;8(I): 80-6. DOI: $10.1016 / j . j d s .2012 .09$. 002.

8. Shahi S, Yavari HR, Rahimi S, Torkamani R. Root canal morphology of human mandibular first permanent molars in an Iranian population. J Dent Res Dent Clin Dent Prospects 2008; 2(I):20-3. DOI: $10.568 \mathrm{I} /$ joddd.2008.004.

9. Hussain $U$, lqbal N, Rehman K. Incidence of fourth canal in mandibular first molar-A Study. Pak Oral Dent J 20 I 3; 33(3):45-9.

10. Al-Qudah A, Awawdeh L.Root and canal morphology of mandibular first and second molar teeth in a Jordanian population. Int Endod J 2009;429(9):775-84. DOI: |0.1|||।/j.|365-2591.2009.01578. $\mathrm{x}$.

II. Hoen MM, Pink PE. Contemporary endodontics retreatment: an analysis based on clinical findings. J 
Endod 2002; 28(I2): 834. DOI: 10.1097/00004770-2002/200000010.

12. Grossman LI, Oliet S, Rio CE. Principles of endodontics practice treatment. II ${ }^{\text {th }}$ ed. 2005; 132-44.

I3. Fava LR, Dummer PM. Periapical radiographic technique during treatment. Int Endod J 1997; 30(4): 250-6I. DOI: I0.1046/j.I3652591.1997.00078.x.

14. Mokhtari H, Niknami M, Zonouzi HR, Sohrabi A, Ghasemi N, Golzar AA. Accuracy of Cone-Beam Computed Tomography in Determining the Root Canal Morphology of Mandibular First Molars. Iran Endod J 2016; II(2):I0I-5. DOI: I0.7508/iej. 2016.02.005.

15. Matherne RP, Angelopoulos C, Kulild JC, Tira D. Use of cone-beam computed tomography to identify root canal systems in vitro. J Endod 2008; 34(I):87-9. DOI: 10.1016/ j.joen.2007.10.016.

16. Kiarudi AH, Eghbal MJ, Safi Y, Aghdasi MM, Fazlyab M. The applications of cone-beam computed tomography in endodontics: a review of literature. Iran Endod J 20 I 5; 10(I): 16-25.

17. Rajput F, Shaikh MA, Shaikh MI, Karim K. Frequency of fourth canal in permanent mandibular first molars. Pak Oral Dent J 20I4;34(I) :|42-6. DOI: $10.568 \mid$ /joddd. 2012.018.

18. Huang CC, Chang YC, Chuang MC, Lai TM, Lai JY, Lee BS, Lin CP. Evaluation of root and canal systems of mandibular first molars in Taiwanese individuals using conebeam computed tomography. J Form Med Assoc 2010; 109(4):3038. DOI: 10.1016/S0929-6646(10) 60056-3.

19. Nur BG, Ok E, Altunsoy M, Aglarci OS, Colak M, Gungor E. Evaluation of the root and canal morphology of mandibular permanent molars in a south-eastern Turkish population using cone-beam computed tomography. Eur J Dent 20 14;8(2): I54. DOI: 10.4/03/1305-7456. 130584.

20. Clarke A, Phillips DI, Brown R, Harper PS. Clinical aspects of $X$ linked hypohidrotic ectodermal dysplasia. Arch Dis Child 1987; 62(10):989-96.
2I. Wasti F, Shearer AC, Wilson NHF. Root canal systems of the mandibular and maxillary first permanent molar teeth of South Asian Pakistanis. Int Endod J 200I; 34(4):263-6. DOI: 10.1046/j.1365259I.200I.00377.x.

22. Gulabivala K, Opassanon A, Ng Y-L, Alavi A. Root and canal morphology of Thai mandibular molars. Int Endod J 2002; 35(I):56-62. DOI: | 0.1046/j.|365-259|.2002. 00452.x.

23. Sert S, Bayirli GS. Evaluation of the root canal configurations of the mandibular and maxillary permanent teeth by gender in the Turkish population. J Endod 2004; 30: 39I-8. DOI: 10.1097/ 00004770-200406000-00004.

24. Torres A, Jacobs R, Lambrechts $P$, Brizuela C, Cabrera C, Concha G, et al. Characterization of mandibular molar root and canal morphology using cone beam computed tomography and its variability in Belgian and Chilean population samples. Imaging Sci Dent 2015 Jun I; 45(2):95-10I. DOI: I0.5624/isd.20I5. 45.2.95.

\section{AUTHORS' CONTRIBUTIONS}

Following authors have made substantial contributions to the manuscript as under:

TM: Concept \& study design, acquisition of data, drafting the manuscript, critical review, final approval of the version to be published.

NN: Acquisition of data, critical review, final approval of the version to be published.

UN: Analysis \& interpretation of data, critical review, final approval of the version to be published.

Authors agree to be accountable for all aspects of the work in ensuring that questions related to the accuracy or integrity of any part of the work are appropriately investigated and resolved

\begin{tabular}{|c|}
\hline CONFLICT OF INTEREST \\
Authors declared no conflict of interest \\
GRANT SUPPORT AND FINANCIAL DISCLOSURE \\
NIL
\end{tabular}

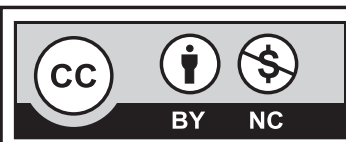

This is an Open Access article distributed under the terms of the Creative Commons Attribution-Non Commercial 2.0 Generic License. 